\title{
A tale of two pancreases: exocrine pathology and endocrine dysfunction
}

\author{
Michael R. Rickels ${ }^{1,2}$ (1) Andrew W. Norris ${ }^{3,4}$ (D) Rebecca L. Hull ${ }^{5,6}$ (D) \\ Received: 2 April 2020 / Accepted: 14 May 2020 / Published online: 31 August 2020 \\ (C) This is a U.S. government work and not under copyright protection in the U.S.; foreign copyright protection may apply 2020
}

\begin{abstract}
The islets of Langerhans are well embedded within the exocrine pancreas (the latter comprised of ducts and acini), but the nature of interactions between these pancreatic compartments and their role in determining normal islet function and survival are poorly understood. However, these interactions appear to be critical, as when pancreatic exocrine disease occurs, islet function and insulin secretion frequently decline to the point that diabetes ensues, termed pancreatogenic diabetes. The most common forms of pancreatogenic diabetes involve sustained exocrine disease leading to ductal obstruction, acinar inflammation, and fibro-fatty replacement of the exocrine pancreas that predates the development of dysfunction of the endocrine pancreas, as seen in chronic pancreatitis-associated diabetes and cystic fibrosis-related diabetes and, more rarely, MODY type 8. Intriguingly, a form of tumour-induced diabetes has been described that is associated with pancreatic ductal adenocarcinoma. Here, we review the similarities and differences among these forms of pancreatogenic diabetes, with the goal of highlighting the importance of exocrine/ductal homeostasis for the maintenance of pancreatic islet function and survival and to highlight the need for a better understanding of the mechanisms underlying these diverse conditions.
\end{abstract}

Keywords Cystic fibrosis · Diabetes $\cdot$ Exocrine $\cdot$ Islet $\cdot$ Pancreas $\cdot$ Pancreatitis $\cdot$ Review
Abbreviations
CEL Carboxyl-ester lipase
CFTR Cystic fibrosis transmembrane
conductance regulator

PP Pancreatic polypeptide

REG3A Regenerating family member $3 \alpha$

\section{Overview}

Electronic supplementary material The online version of this article (https://doi.org/10.1007/s00125-020-05210-8) contains a slide of the figure for download, which is available to authorised users.

Rebecca L. Hull

rhull@uw.edu

1 Department of Medicine, Hospital of the University of Pennsylvania, Philadelphia, PA, USA

2 Institute for Diabetes, Obesity \& Metabolism, University of Pennsylvania Perelman School of Medicine, Philadelphia, PA, USA

3 Department of Pediatrics, University of Iowa, Iowa City, IA, USA

4 Fraternal Order of Eagles Diabetes Research Center, University of Iowa, Iowa City, IA, USA

5 VA Puget Sound Health Care System (151), 1660 S. Columbian Way, Seattle, WA 98108, USA

6 Department of Medicine, University of Washington, Seattle, WA, USA
Under normal conditions, the exocrine (acinar and ductal) and endocrine pancreas co-exist in harmony (Fig. 1a,c). The organisation of these pancreatic compartments is the topic of some excellent reviews $[1,2]$ and is not covered here. The nature of the interactions between exocrine and endocrine pancreas and the role thereof in homeostatic pancreatic function remain incompletely understood. Surgical resection of up to $50 \%$ of the pancreas does not necessarily lead to diabetes [3], suggesting there is considerable functional reserve.

Insufficient insulin secretion is the unifying defect in all forms of diabetes, such as autoimmune destruction of islet beta cells in type 1 diabetes or intrinsic and acquired beta cell dysfunction in type 2 diabetes. Beta cell dysfunction/ deficiency can also occur secondary to exocrine pancreatic disease, leading to pancreatogenic diabetes, also known as type $3 c$ diabetes [4-6]. Of note, average pancreatic volume is decreased in people with type 1 or type 2 diabetes compared 


\section{Key points}

- Islets in context: Pancreatic islets exist within the exocrine pancreas, but the role of interactions between the exocrine and endocrine pancreas in determining normal islet health and function is poorly understood

- Pancreatogenic diabetes: A diverse array of exocrine pancreas diseases results in impaired insulin secretion and, ultimately, diabetes, providing evidence that endocrine/exocrine interactions are indeed critical for normal islet function

- $\quad$ Clues to underlying mechanisms: The underlying causes of the various forms of pancreatogenic diabetes are poorly understood, but emerging data highlight the importance of paracrine interactions between ductal epithelial cells and beta cells and/or islet inflammation

- $\quad$ Therapeutic considerations: Current treatment options for pancreatogenic diabetes are limited. Better understanding of diabetes-causing mechanisms are needed to develop diabetes prevention strategies and improved treatment approaches in these populations

with that in non-diabetic control individuals [7, 8], supporting a bi-directional interaction between the endocrine and exocrine pancreas; however, discussion of this is beyond the scope of this article. Here we review several forms of pancreatogenic diabetes, highlighting the importance of the exocrine pancreas for the maintenance of pancreatic islet beta cell function and mass. Furthermore, we explore the similarities and differences in the aetiology of these diseases, with the goal of improving our understanding of interactions between pancreatic acini/ducts and islets in health and disease.

\section{Chronic pancreatitis-associated diabetes}

Diabetes develops in 26-80\% of patients with chronic pancreatitis, with a higher prevalence seen with alcohol-related disease, early development of pancreatic calcifications, and longer disease duration; the majority develop diabetes by the fifth decade of life [9-11]. Compared with chronic pancreatitis, a single episode of acute pancreatitis confers a lower risk of diabetes [12]; this occurs predominantly in patients exhibiting marked tissue destruction.

Chronic pancreatitis generally follows a period of recurrent episodes of acute pancreatitis that may not always be appreciated clinically. These episodes of acute acinar injury and ductal plugging by concretions eventually result in ongoing pancreatic inflammation resulting in acinar destruction and fibrosis (Fig. 1b,d). While chronic alcohol use is the most common underlying aetiology, pancreatic injury also occurs in disorders that affect pancreatic duct flow (duct scars, pancreas divisum and groove pancreatitis), tropical calcific pancreatitis endemic to regions of Asia and Africa, hereditary pancreatitis (i.e. PRSS1, SPINK1, CFTR and CTRC mutations [OMIM no. 167800; www.omim.org]) and idiopathic causes (reviewed in [13]). Most often, more than one genetic and/or environmental factor contribute to the development of pancreatitis [13]. Despite the varied underlying causes, as recurrent acute becomes chronic pancreatitis, dysfunction of the pancreatic duct leads to ongoing destruction and dysfunction of the exocrine pancreas.

Patients with chronic pancreatitis-associated diabetes may have a known history of pancreatitis and exocrine insufficiency resulting in steatorrhoea. In addition, patients without a prior diagnosis of pancreatitis may present with abdominal pain and/or symptoms of maldigestion or may only present with glucose intolerance/diabetes. While weight gain typically accompanies the onset of type 2 diabetes, weight loss can occur in those with severe hyperglycaemia. Despite this, reduced weight occurring at the time of diabetes diagnosis should prompt careful clinical evaluation for the presence of underlying pancreatic disease. Diagnostic criteria for chronic pancreatitis-associated diabetes include the presence of pancreatic exocrine insufficiency, pathological pancreatic imaging and absence of type 1 diabetes-associated autoantibodies [14]. Pancreatic enzyme replacement in pancreatogenic diabetes is important to address maldigestion and malabsorption (particularly of fat and fat-soluble vitamins such as vitamin D) and control symptoms of steatorrhoea, and to improve incretin hormone secretion and, consequently, insulin release, which ultimately improves glucose tolerance [15].

\section{Cystic fibrosis-related diabetes}

Diabetes affects $20 \%$ of adolescents and $\sim 50 \%$ of adults with cystic fibrosis [16]. Cystic fibrosis occurs due to biallelic lossof-function mutations in the cystic fibrosis transmembrane conductance regulator (CFTR). This disrupts anion transport across epithelial cells, predominantly in the pancreas, lung and gut, and results in severe, multiorgan disease that leads to premature death, usually due to lung disease [17]. One of the earliest manifestations of cystic fibrosis is the dilation of pancreatic ducts and ductal obstruction due to plugging with 


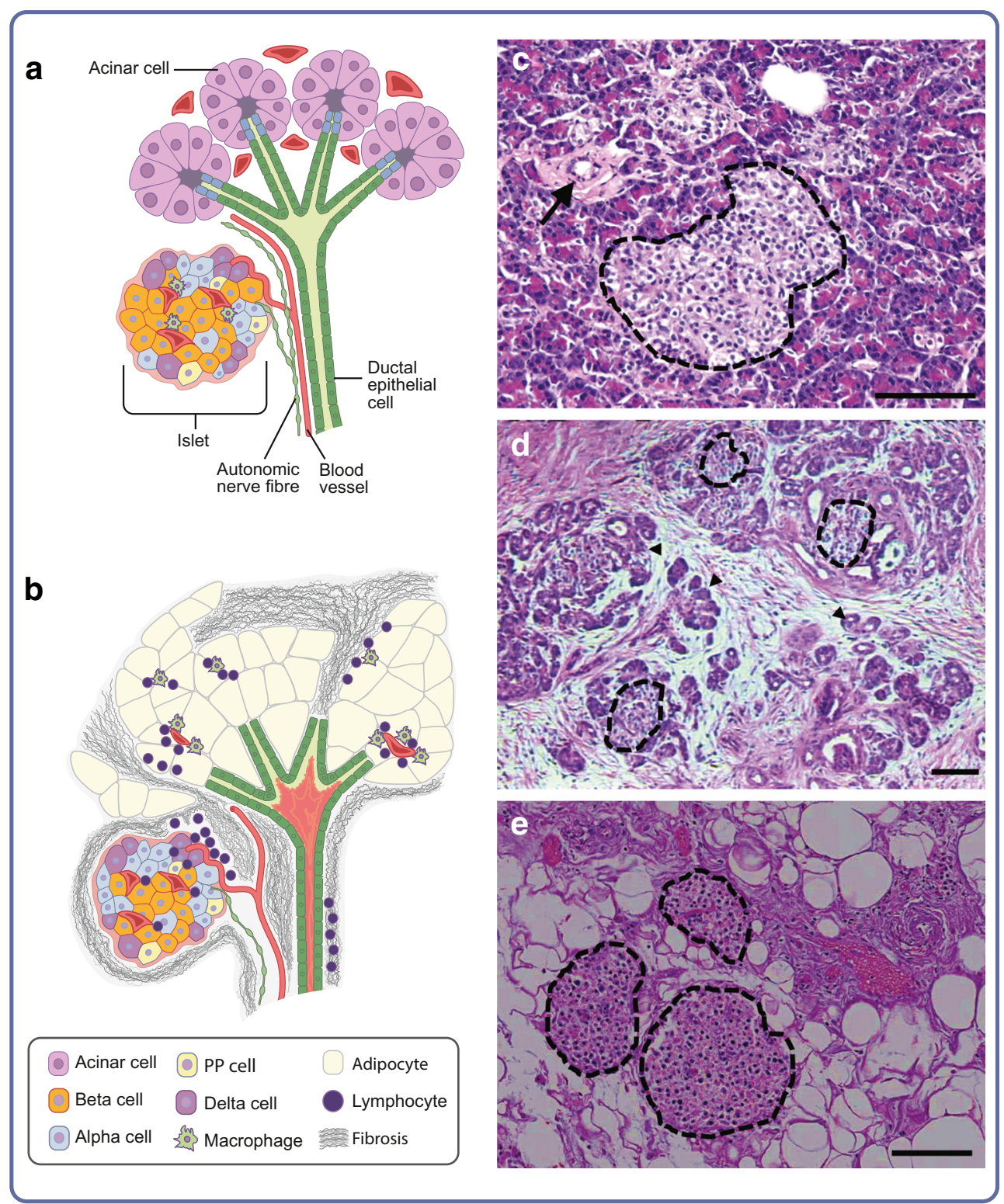

Fig. 1 Schematic showing normal pancreatic morphology (a) with close proximity between pancreatic ducts, acini and islets, the latter comprising beta cells, alpha cells, delta cells and PP cells with resident macrophages (cell types shown in key). Capillaries and autonomic nerve fibres supply all pancreatic compartments. Generalised alterations in pancreatic morphology that occur with pancreatogenic diabetes (b), i.e. ductal plugging (shown in pink within the duct lumen)/dilation, fibro-fatty replacement of acinar tissue and lymphocyte infiltration, with macrophages in the exocrine pancreas but not within the islet, and islet remodelling (modest loss of beta cells and increase in alpha cells). Micrographs

viscous secretions [18]. This ductal pathology leads to fibrofatty replacement of acinar tissue (Fig. 1b,e) and pancreatic insufficiency in $\sim 85 \%$ of individuals [19]. While CFTR mutations resulting in complete or near-complete loss of CFTR function lead to exocrine pancreas destruction very early in life, less severe CFTR mutations may be associated with pancreatitis later in life, or spare the pancreas even when sinopulmonary disease is present [20]. Clinically evident showing H\&E-stained pancreas sections from a control individual without pancreatic disease (c) an individual with chronic pancreatitis (d) and a person with cystic fibrosis (e). Islets are demarcated with dotted black lines, a normal duct is shown with an arrow in (c), fibrosis is shown surrounding degenerating acini (the latter denoted by arrowheads) in (d) and extensive fatty replacement of exocrine pancreas is shown in (e). Strikingly, despite the severe disruption to the exocrine pancreas in (d) and (e), islets remain readily visible. Scale bar, $100 \mu \mathrm{m}$. This figure is available as a downloadable slide

pancreatitis is uncommon in individuals with pancreaticinsufficient cystic fibrosis. As described above for chronic pancreatitis with pancreatic exocrine insufficiency, pancreatic enzyme replacement improves incretin secretion and thereby insulin release that is beneficial for glucose tolerance [21].

Of particular concern, cystic fibrosis-related diabetes is associated with decreased lung function, increased pulmonary exacerbations, increased catabolism, lower BMI and an 
approximately four-fold increase in mortality risk [22] relative to individuals with cystic fibrosis without diabetes. Moreover, the presence of abnormal glucose tolerance is also associated with a significant decline in lung function [23], worse survival and higher lung transplant rates [24], illustrating that even mild abnormalities in glucose metabolism have adverse effects on cystic fibrosis outcomes. Although the risk of diabetes in individuals with cystic fibrosis increases with CFTR mutation severity, the increase in mortality risk induced by diabetes is independent of CFTR mutation severity; even among those with severe mutations, the presence of diabetes significantly increases mortality risk [22].

\section{Rarer forms of pancreatogenic diabetes}

Several rare pancreatic diseases provide additional evidence that healthy exocrine tissue supports the maintenance of islet function and glucose homeostasis.

Autoimmune pancreatitis is often accompanied by diabetes [25]. Type 1 autoimmune pancreatitis is associated with antibodies against lactoferrin, carbonic anhydrase II or $\alpha$-2Aamylase and a lymphoplasmacytic sclerosing pancreatitis histopathology (reviewed in [26]). Type 2 autoimmune pancreatitis has negative serology and shows idiopathic duct-centric pancreatitis with granulocytic epithelial lesions [27]. In autoimmune pancreatitis, although islet-directed antibodies are not present [26], pancreatic histopathology shows inflammatory cells in contact with islets and loss of beta cells. Importantly, glucocorticoids not only alleviate pancreatitis in autoimmune pancreatitis, but also improve insulin secretion and help resolve diabetes [28].

MODY type 8 (MODY8, OMIM no. 609812) is caused by mutations in carboxyl-ester lipase (CEL) [29]. CEL is released from acinar cells, and is the only pancreatic bile-activated lipase present in ductal secretions. Despite a lack of clinically detectable pancreatitis, individuals with MODY8 develop slowly progressive pancreatic insufficiency, pancreatic cysts, fibro-fatty replacement of acinar tissue and insulin deficiency [30]. Mechanistic understanding of this insulin deficiency has been hampered by the fact that pancreas-specific $\mathrm{Ce}^{--}$mice do not recapitulate the exocrine disease or diabetes seen in humans [31], a shortcoming also seen in mouse models of other pancreatic diseases (e.g. $\mathrm{Cftr}^{-1-}$ mice).

Two additional forms of MODY highlight the shared developmental aspects of the endocrine and exocrine pancreas and are important to consider, especially in young people presenting with deficient exocrine and endocrine pancreas function. MODY4 (OMIM no. 606392) is caused by heterozygous mutations in pancreatic and duodenal homeobox 1 (PDX1). Homozygous mutations cause pancreatic agenesis, including absence of both exocrine and endocrine components [32]. Similarly, MODY5 (OMIM no. 137920), caused by heterozygous mutations in HNF1 homeobox B (HNF1B), is associated with mild pancreatic exocrine deficiency and frequent aplasia of the body and tail of the pancreas [33].

\section{Pancreatic ductal adenocarcinoma-associated diabetes}

Pancreatic ductal adenocarcinoma is the most common and lethal form of pancreatic cancer and shares a bi-directional association with diabetes. Obesity and type 2 diabetes are risk factors for pancreatic ductal adenocarcinoma, with insulin resistance and the resultant hyperinsulinaemia promoting tumour survival/proliferation, via insulin and IGF-1 receptor signalling [34]. Intriguingly, there is also evidence that pancreatic ductal adenocarcinoma may lead to the development of diabetes via a paraneoplastic effect of the developing tumour on islet beta cell function. In support of this, recent evidence shows bi-directional blood flow in the pancreas [35]. This provides a mechanism for delivery of high levels of insulin (and other beta cell products, such as cholecystokinin [36]) from the beta cell to acinar/ductal/tumour cells, along with the supply of tumour-derived factors to the beta cell.

Diabetes is present more often at diagnosis of pancreatic ductal adenocarcinoma than other cancers [37]. Among individuals with pancreatic ductal adenocarcinoma and diabetes, the majority were diagnosed with diabetes within 24 months prior to cancer diagnosis and often presented with weight loss at the time of diabetes diagnosis [6]. Thus, as discussed above, when patients present at diabetes diagnosis with disproportionate weight loss (relative to diabetes severity), pancreatic imaging not only allows for assessment of pancreatogenic diabetes but may also allow for early detection of pancreatic cancer.

\section{Islet failure in pancreatogenic forms of diabetes}

The aetiology of islet beta cell failure in pancreatogenic diabetes remains poorly understood. Most studies relate to chronic pancreatitis and especially cystic fibrosis, with potential novel mechanisms emerging from several recent studies, as described in the next section.

In both chronic pancreatitis and cystic fibrosis, fibrotic and/ or fatty replacement of acinar tissue disrupts normal pancreas microarchitecture, resulting in progressive exocrine dysfunction. This results in nutrient maldigestion/malabsorption and contributes to the development of impaired glucose intolerance and, eventually, diabetes. Measures of pancreatic exocrine and endocrine function (Table 1) are significantly correlated in chronic pancreatitis $[38,39]$ and insulin secretion is significantly worse in individuals with cystic fibrosis with 
Table 1 Methods for clinical assessment of pancreatic exocrine and endocrine function

\section{Exocrine function test \\ Immunoreactive trypsinogen}

CFTR mutation analysis

Pancreatic faecal elastase

Faecal fat test

Direct pancreatic function test

Endocrine function tests $\mathrm{HbA}_{1 \mathrm{c}}$

Fasting glucose

2 h OGTT glucose

$1 \mathrm{~h}$ OGTT glucose

Fasting insulin or C-peptide

Stimulated C-peptide

Stimulated PP
Neonatal screening test for $\mathrm{CF}$ based on heel prick. Elevated blood levels from impaired pancreatic duct drainage may be seen in carriers of heterozygous CFTR mutations and this test does not distinguish between pancreatic-sufficient and -insufficient CF, so confirmation testing by CFTR mutation analysis and/or sweat testing is required.

Class I-III 'severe' mutations are associated with pancreatic insufficiency in CF, whereas the presence of at least one class IV-V mutation, resulting in partially functional CFTR, is required for pancreatic-sufficient CF.

Levels $>200 \mu \mathrm{g}$ elastase $/ \mathrm{g}$ faecal material are consistent with normal, 100-200 $\mu \mathrm{g}$ elastase/g faecal material indeterminate, and $<100 \mu \mathrm{g}$ elastase/g faecal material insufficient pancreatic exocrine function.

Requires $72 \mathrm{~h}$ stool collection. Elevated in pancreatic insufficiency due to maldigestion from loss of pancreatic lipase activity but is also elevated by malabsorption in disorders of the small intestine (e.g. coeliac disease, bacterial overgrowth, short bowel syndrome).

Requires upper gastrointestinal endoscopy. Measures pancreatic secretion of bicarbonate or lipase into the duodenum following stimulation with i.v. secretin or cholecystokinin (CCK), respectively. More likely to be reduced early in the development of pancreatic exocrine disease than indirect tests (faecal elastase, faecal fat).

Standard screening test with criteria for defining normal $(<5.7 \%[<39 \mathrm{mmol} / \mathrm{mol}])$, increased risk of diabetes $(5.7-6.4 \%[39-47 \mathrm{mmol} / \mathrm{mol}])$ and diabetes $(\geq 6.5 \%$ $[\geq 48 \mathrm{mmol} / \mathrm{mol}])$. Less sensitive than OGTT measures in patients with pancreatic exocrine disease.

Standard screening test with criteria for defining normal $(<5.6 \mathrm{mmol} / 1[100 \mathrm{mg} / \mathrm{dl}])$, impaired fasting glucose $(5.6-6.9 \mathrm{mmol} / \mathrm{l}[100-125 \mathrm{mg} / \mathrm{dl}])$ and diabetes $(\geq 7.0 \mathrm{mmol} / 1[126 \mathrm{mg} / \mathrm{dl}])$. Less sensitive than OGTT measures in patients with pancreatic exocrine disease.

Standard screening test with criteria for defining normal (<7.8 mmol/1 [140 mg/dl]), impaired glucose tolerance $(7.8-11.0 \mathrm{mmol} / \mathrm{l}[140-199 \mathrm{mg} / \mathrm{dl}])$ and diabetes $(11.1 \mathrm{mmol} / \mathrm{l}[\geq 200 \mathrm{mg} / \mathrm{dl}])$. Consider whenever the $\mathrm{HbA}_{\mathrm{lc}}$ or fasting glucose indicates increased risk, and use annually in $\mathrm{CF}$ to evaluate for the presence of diabetes.

Non-standard screening test useful for defining early glucose intolerance ( $\geq 8.6 \mathrm{mmol} / 1[155 \mathrm{mg} / \mathrm{dl}])$ in $\mathrm{CF}$ and chronic pancreatitis. Consider including as part of any OGTT performed in individuals with pancreatic disease.

Useful with fasting glucose to derive homeostatic model assessment indices of beta cell function (HOMA-B) and insulin resistance (HOMA-IR) that can help to distinguish pancreatogenic from type 2 diabetes.

Useful 60 or $90 \mathrm{~min}$ after OGTT or MMTT as an estimate of beta cell secretory reserve, in particular as part of the evaluation and follow-up for individuals with chronic pancreatitis considering total pancreatectomy with islet autotransplantation, where outcomes are dependent on isolated and engrafted islet beta cell mass.

Useful 60 or 90 min after MMTT as a marker of pancreatic disease affecting islet function. In the presence of diabetes, an absent PP response is a specific indicator of pancreatogenic diabetes.

OGTT refers to the standard test of $1.75 \mathrm{~g} / \mathrm{kg}$ up to $75 \mathrm{~g}$ ingested over $5 \mathrm{~min}$

CF, cystic fibrosis; MMTT, mixed-meal tolerance test, standard $6 \mathrm{ml} / \mathrm{kg}$ up to $360 \mathrm{ml}$ (12 oz) Boost High Protein or equivalent ingested over $5 \mathrm{~min}$ (with prescribed pancreatic enzymes for those with established pancreatic exocrine insufficiency)

pancreatic insufficiency [40], providing additional evidence for the interrelated pathology of the islet and exocrine pancreas.

Impaired insulin secretion is the key defect underlying the development of hyperglycaemia in both chronic pancreatitis and cystic fibrosis. In chronic pancreatitis, impaired insulin secretion is evident even without the presence of diabetes [41]. In cystic fibrosis, impaired insulin secretion is present in most individuals [40, 42-44], including young children [40, 43]. In cystic fibrosis, beta cell function is progressively 
impaired across the glucose tolerance spectrum, beginning with an elevated $1 \mathrm{~h}$ OGTT and ultimately resulting in cystic fibrosis-related diabetes [44]. Despite substantial destruction of exocrine pancreas in both chronic pancreatitis and cystic fibrosis, the loss of islet beta cells is generally modest, even in individuals with long-standing pancreatic disease (reviewed in $[45,46])$. Thus, while a reduction in beta cell mass may contribute to the loss of insulin release in chronic pancreatitis and cystic fibrosis, it is unlikely to be the sole cause. In addition, there may be dynamic developmental changes in islet mass in cystic fibrosis pancreatic disease. Histopathological investigation of the pancreas of young children with cystic fibrosis resulted in the hypothesis that new islet formation was occurring [47]. Similarly, young ferrets with cystic fibrosis undergo loss of detectable pancreatic endocrine cells during active exocrine tissue destruction, followed by a transient expansion of beta cells [48]. The source of these new islets remains uncertain.

In chronic pancreatitis, the mechanism(s) underlying insulin secretory dysfunction is very poorly understood although, as mentioned above, decreased beta cell number and function both contribute (reviewed in [45]). In cystic fibrosis, more is known, although whether insulin secretory defects occur as a result of the effect of mutated CFTR within the beta cell itself is controversial. Several studies have reported beta cell CFTR activity and an effect on insulin release from human and rodent islets [49-51], and CFTR corrector therapy has been shown to rescue defective insulin release in a mouse model of cystic fibrosis [50]. Some of these data must be interpreted with caution due to reliance on pharmacological inhibitors (CFTR(inh)-172 or GlyH-101) and/or CFTR antibodies that lack specificity $([52,53]$ and reviewed in $[46])$. In contrast, numerous recent studies show that beta cell CFTR expression is exceedingly low/difficult to detect. These studies utilised in situ hybridisation [53, 54], immunohistochemistry [52, 54, 55] and/or analysis of datasets comprising single cell or bulk islet RNA-seq data $[46,52]$. In addition, a recent study did not find a CFTR current in human beta cells [52] and beta cell deletion of $C$ ftr did not affect insulin release in a mouse model [52]. Taken together, these data suggest that effects of CFTR within beta cells is unlikely to be the sole cause of insulin secretory dysfunction. However, these findings could also be explained by beta cell subpopulation heterogeneity (i.e. CFTR being expressed in a small subset of beta cells, which could have large functional effects).

Non-beta cell intrinsic mechanisms are also likely to contribute to dysfunctional insulin secretion in pancreatogenic diabetes. Recent studies in cystic fibrosis models have suggested the presence of paracrine crosstalk between pancreatic ductal epithelial cells and beta cells $[46,53,55]$, suggesting that alterations in secreted factors from diseased ducts could be a common mechanism underlying impaired insulin release in this and other pancreatogenic forms of diabetes, although the mechanisms underlying this crosstalk are entirely unknown. In addition, as pancreatic exocrine insufficiency predates the development of diabetes in both chronic pancreatitis and cystic fibrosis, the associated impairment in incretin secretion may chronically affect islet beta cell mass and function through disruption of the enteroinsular axis.

Another possibility involves the loss of exocrine-derived paracrine factors that support islet maintenance and function. One potential example is regenerating family member $3 \alpha$ (REG3A), also known as islet neogenesis associated protein (INGAP), an exocrine-derived paracrine factor whose expression is upregulated in perturbed acinar cells and which positively impacts islet mass [56]. However, it could be the case that in pancreatic disease associated with loss of exocrine tissue, REG3A is no longer synthesised, resulting in deficiency of this islet-protective factor.

Islet dysfunction in chronic pancreatitis and cystic fibrosis is not limited to the beta cell. While basal and stimulated glucagon release is increased with acute pancreatitis [57], glucagon release is reduced in chronic pancreatitis, especially in the presence of diabetes $[57,58]$. In cystic fibrosis, glucagon release in response to arginine or following hypoglycaemia is reduced $[40,42,59]$. This defective glucagon release does not occur secondary to a loss of alpha cells. Rather, in chronic pancreatitis, alpha cell number is increased relative to islet area [60], while in cystic fibrosis an absolute increase in alpha cell number is evident (reviewed in [46]). In addition, impaired suppression of glucagon release may occur due to insulin deficiency in both chronic pancreatitis [61] and cystic fibrosis [62]. In line with this latter point, use of the CFTR modulator ivacaftor in individuals with cystic fibrosis improved insulin secretion, which was associated with more appropriate glucagon suppression [63].

CFTR corrector/potentiator therapies dramatically improve cystic fibrosis lung disease. Very limited data are available regarding the impact of these drugs on glucose tolerance/ islet function, but positive effects are suggested [63, 64]. Additional studies are needed to uncover the mechanism of action and optimal age for treatment initiation for this new class of drugs.

In chronic pancreatitis, exocrine pancreas destruction and associated loss of nerve bundles is associated with the loss of islet vascularity and innervation [60]. Consequently, a profound loss of pancreatic polypeptide (PP) secretion, which depends on vagal afferents, is observed $[65,66]$. This could also be related to destruction of the ventral pancreas, where the majority of PP-rich islets are located. In chronic pancreatitis, reduced PP secretion is seen early in the course of the disease [66], with PP responses being essentially absent when glucose tolerance is also impaired [65]. Similarly, in pancreaticinsufficient cystic fibrosis, a marked defect in PP cell function is also observed, regardless of glucose tolerance status [42, 67]. The underlying mechanism is less well understood in 
cystic fibrosis, but animal studies suggest loss of pancreatic/ islet innervation [68]. Thus, decreased PP secretion appears to be a reliable early marker for endocrine dysfunction in these two pancreatic diseases [4, 42, 67].

\section{Potential mechanisms underlying beta cell failure}

Recent publications have begun to elucidate mechanisms that may underlie beta cell (and alpha cell failure) in chronic pancreatitis and cystic fibrosis. A small pancreatic histopathology study of chronic pancreatitis cases demonstrated increased inflammatory infiltration near islets (much greater than that seen in type 2 diabetes), along with a significant increase in 'dedifferentiated' cells, specifically chromogranin A-positive, hormone-negative cells [69]. For cystic fibrosis, recent studies demonstrated that islet inflammation, namely, increased IL-1 $\beta$ immunoreactivity (likely within beta cells) [70] and/or increased $\mathrm{T}$ cell presence (including cytotoxic $\mathrm{CD} 8^{+} \mathrm{T}$ cells) $[52,71]$, are early and common features of islet pathology in individuals with cystic fibrosis both with and without diabetes. The underlying aetiology of this islet cytokine expression/lymphocyte infiltration is currently unknown. Amyloid deposition within islets, a pathological hallmark of type 2 diabetes known to be associated with leucocyte activation, is present but does not correlate with islet IL-1 $\beta$ immunoreactivity in cystic fibrosis [70] and has not been widely studied in chronic pancreatitis. Islet macrophages are well known for production of proinflammatory cytokines [72], but are also required for islet regeneration [73, 74] and have been shown to stimulate islet angiogenesis and protect against islet cell loss during exocrine pancreas disease in mice [75]. Of note, macrophages are almost entirely absent from islets in adults with cystic fibrosis [70,71]. Together, these new data suggest that strategies aimed at reducing islet cytokine expression, limiting $\mathrm{T}$ cell infiltration and/or replenishing islet macrophages could be effective in restoring beta cell function in pancreatogenic diabetes, although additional studies are needed to better define the underlying aetiology of islet inflammation in these disease states.

The mechanisms underlying pancreatic ductal adenocarcinoma-associated diabetes remain unknown. The observation that new-onset diabetes in pancreatic ductal adenocarcinoma can resolve following tumour resection when sufficient residual pancreatic tissue remains supports a paraneoplastic mechanism [6]. However, this effect is invariably reported following pancreaticoduodenectomy and so is confounded by independent effects of Roux-en-Y reconstruction with gastrojejunostomy on glucose homeostasis as seen with bariatric surgery [76]. In vitro evidence suggests that tumours may release peptide- and cytokine-containing exosomes that may result in impaired islet beta cell function [77], in an analogous fashion to the duct-islet paracrine interaction proposed for cystic fibrosis above, while histological examination of paraneoplastic pancreatic tissue resected from individuals with pancreatic ductal adenocarcinoma without diabetes demonstrates islet infiltration with an inflammatory cell infiltrate and reduced markers of differentiated beta cell identity [78], reminiscent of data from both chronic pancreatitis and cystic fibrosis. Increases in fasting glucose are detectable 3 years prior to diagnosis of pancreatic ductal adenocarcinoma [79], and whether this deterioration in glucose homeostasis may be combined with other potential cancer biomarkers to inform early diagnosis is under active clinical investigation [80].

\section{Summary and implications}

Diabetes occurs secondary to a collection of seemingly disparate diseases that affect pancreatic ducts and/or acini. Amazingly, islets generally survive within this diseased organ, albeit in a dysfunctional state. However, as pancreatic exocrine disease progresses, islet function becomes impaired, leading to pancreatogenic diabetes. This implies a functional connection between the two pancreatic compartments. Further study is needed to better understand the mechanistic links between these two entities, with the goal of developing better preventative/curative strategies for those affected by the diseases reviewed herein.

Acknowledgements Due to the limit on the number of references allowed, many excellent papers in this field could not be included. However, these additional publications were important in shaping this review; we apologise to those whose work was not cited directly. We thank C. Liu of the Department of Surgery, University of Pennsylvania Perelman School of Medicine, for supplying images from H\&E-stained control and chronic pancreatitis pancreas specimens.

Funding Work in the authors' laboratories is supported by National Institutes of Health grants R01 DK97830 (MRR), R01 DK115791 (AWN), and R01 DK088082 (RLH). AWN is also supported by the Fraternal Order of Eagles Diabetes Research Center. RLH is also supported by the Department of Veterans Affairs, VA Puget Sound Health Care System (Seattle, WA, USA) and Seattle Institute for Biomedical and Clinical Research (Seattle, WA, USA).

Authors' relationships and activities The authors declare that there are no relationships or activities that might bias, or be perceived to bias, their work.

Contribution statement All authors developed the outline of the article, reviewed and discussed the relevant literature, and were responsible for drafting the article and revising it critically for important intellectual content. All authors approved the version to be published.

\section{References}

1. Longnecker DS (2014) Anatomy and histology of the pancreas. Available from www.pancreapedia.org/reviews/anatomy-andhistology-of-pancreas. Accessed 17 May 2020 
2. El-Gohary Y, Gittes GK (2018) Structure of islets and vascular relationship to the exocrine pancreas. Available from www. pancreapedia.org/reviews/structure-of-islets-and-vascularrelationship-to-exocrine-pancreas. Accessed 17 May 2020

3. Seaquist ER, Robertson RP (1992) Effects of hemipancreatectomy on pancreatic alpha and beta cell function in healthy human donors. J Clin Invest 89(6):1761-1766. https://doi.org/10.1172/JCI1 15779

4. Rickels MR, Bellin M, Toledo FGS et al (2013) Detection, evaluation and treatment of diabetes mellitus in chronic pancreatitis: recommendations from PancreasFest 2012. Pancreatology 13(4): 336-342. https://doi.org/10.1016/j.pan.2013.05.002

5. Moran A, Hardin D, Rodman D et al (1999) Diagnosis, screening and management of cystic fibrosis related diabetes mellitus: a consensus conference report. Diabetes Res Clin Pract 45(1):6173. S0168822799000583 [pii]. https://doi.org/10.1016/S01688227(99)00058-3

6. Pannala R, Leirness JB, Bamlet WR, Basu A, Petersen GM, Chari ST (2008) Prevalence and clinical profile of pancreatic cancerassociated diabetes mellitus. Gastroenterology 134(4):981-987. https://doi.org/10.1053/j.gastro.2008.01.039

7. Lu J, Guo M, Wang $\mathrm{H}$ et al (2019) Association between pancreatic atrophy and loss of insulin secretory capacity in patients with type 2 diabetes mellitus. J Diabetes Res 2019:6371231-6371236. https:// doi.org/10.1155/2019/6371231

8. Virostko J, Williams J, Hilmes M et al (2019) Pancreas volume declines during the first year after diagnosis of type 1 diabetes and exhibits altered diffusion at disease onset. Diabetes Care 42(2):248-257. https://doi.org/10.2337/dc18-1507

9. Wakasugi H, Funakoshi A, Iguchi H (1998) Clinical assessment of pancreatic diabetes caused by chronic pancreatitis. J Gastroenterol 33(2):254-259. https://doi.org/10.1007/s005350050079

10. Malka D, Hammel P, Sauvanet A et al (2000) Risk factors for diabetes mellitus in chronic pancreatitis. Gastroenterology 119(5): 1324-1332. https://doi.org/10.1053/gast.2000.19286

11. Howes N, Lerch MM, Greenhalf W et al (2004) Clinical and genetic characteristics of hereditary pancreatitis in Europe. Clin Gastroenterol Hepatol 2(3):252-261. https://doi.org/10.1016/ S1542-3565(04)00013-8

12. Das SL, Singh PP, Phillips AR, Murphy R, Windsor JA, Petrov MS (2014) Newly diagnosed diabetes mellitus after acute pancreatitis: a systematic review and meta-analysis. Gut 63(5):818-831. https:// doi.org/10.1136/gutjnl-2013-305062

13. Whitcomb DC (2013) Genetic risk factors for pancreatic disorders. Gastroenterology 144(6):1292-1302. https://doi.org/10.1053/j. gastro.2013.01.069

14. Ewald N, Bretzel RG (2013) Diabetes mellitus secondary to pancreatic diseases (type 3c) - are we neglecting an important disease? European Eur J Intern Med 24(3):203-206. https://doi.org/10.1016/ j.ejim.2012.12.017

15. Knop FK, Vilsboll T, Larsen S et al (2007) Increased postprandial responses of GLP-1 and GIP in patients with chronic pancreatitis and steatorrhea following pancreatic enzyme substitution. Am J Physiol Endocrinol Metab 292(1):E324-E330. https://doi.org/10. 1152/ajpendo.00059.2006

16. Moran A, Dunitz J, Nathan B, Saeed A, Holme B, Thomas W (2009) Cystic fibrosis-related diabetes: current trends in prevalence, incidence, and mortality. Diabetes Care 32(9):1626-1631. https:// doi.org/10.2337/dc09-0586

17. Elborn JS (2016) Cystic fibrosis. Lancet 388(10059):2519-2531. https://doi.org/10.1016/S0140-6736(16)00576-6

18. Andersen DH (1958) Cystic fibrosis of the pancreas. J Chronic Dis 7(1):58-90. https://doi.org/10.1016/0021-9681(58)90185-1

19. Singh VK, Schwarzenberg SJ (2017) Pancreatic insufficiency in cystic fibrosis. J Cyst Fibros 16(Suppl 2):S70-S78. https://doi. org/10.1016/j.jcf.2017.06.011
20. Durno C, Corey M, Zielenski J, Tullis E, Tsui LC, Durie P (2002) Genotype and phenotype correlations in patients with cystic fibrosis and pancreatitis. Gastroenterology 123(6):1857-1864. https://doi. org/10.1053/gast.2002.37042

21. Perano SJ, Couper JJ, Horowitz M et al (2014) Pancreatic enzyme supplementation improves the incretin hormone response and attenuates postprandial glycemia in adolescents with cystic fibrosis: a randomized crossover trial. J Clin Endocrinol Metab 99(7):24862493. https://doi.org/10.1210/jc.2013-4417

22. Lewis C, Blackman SM, Nelson A et al (2015) Diabetes-related mortality in adults with cystic fibrosis. Role of genotype and sex. Am J Respir Crit Care Med 191(2):194-200. https://doi.org/10. 1164/rccm.201403-0576OC

23. Brodsky J, Dougherty S, Makani R, Rubenstein RC, Kelly A (2011) Elevation of 1-hour plasma glucose during oral glucose tolerance testing is associated with worse pulmonary function in cystic fibrosis. Diabetes Care 34(2):292-295. https://doi.org/10. $2337 / \mathrm{dc} 10-1604$

24. Bismuth E, Laborde K, Taupin P et al (2008) Glucose tolerance and insulin secretion, morbidity, and death in patients with cystic fibrosis. J Pediatr 152(4):540-545, 545. https://doi.org/10.1016/j.jpeds. 2007.09.025

25. Kawa S, Maruyama M, Watanabe T (2013) Prognosis and long term outcomes of autoimmune pancreatitis. Available from www. pancreapedia.org/reviews/prognosis-and-long-term-outcomes-ofautoimmune-pancreatitis. Accessed 17 May 2020

26. Smyk DS, Rigopoulou EI, Koutsoumpas AL, Kriese S, Burroughs AK, Bogdanos DP (2012) Autoantibodies in autoimmune pancreatitis. Int J Rheumatol 2012:940831-940838. https://doi.org/10. 1155/2012/940831

27. Matsubayashi H, Ishiwatari H, Imai K et al (2019) Steroid therapy and steroid response in autoimmune pancreatitis. Int J Mol Sci 21(1):E257. https://doi.org/10.3390/ijms21010257

28. Tanaka S, Kobayashi T, Nakanishi K et al (2000) Corticosteroidresponsive diabetes mellitus associated with autoimmune pancreatitis. Lancet 356(9233):910-911. https://doi.org/10.1016/S01406736(00)02684-2

29. Johansson BB, Fjeld K, El Jellas K et al (2018) The role of the carboxyl ester lipase (CEL) gene in pancreatic disease. Pancreatology 18(1):12-19. https://doi.org/10.1016/j.pan.2017.12. 001

30. Raeder H, McAllister FE, Tjora E et al (2014) Carboxyl-ester lipase maturity-onset diabetes of the young is associated with development of pancreatic cysts and upregulated MAPK signaling in secretin-stimulated duodenal fluid. Diabetes 63(1):259-269. https://doi.org/10.2337/db13-1012

31. Raeder H, Vesterhus M, El Ouaamari A et al (2013) Absence of diabetes and pancreatic exocrine dysfunction in a transgenic model of carboxyl-ester lipase-MODY (maturity-onset diabetes of the young). PLoS One 8(4):e60229. https://doi.org/10.1371/journal. pone.0060229

32. Wright NM, Metzger DL, Borowitz SM, Clarke WL (1993) Permanent neonatal diabetes mellitus and pancreatic exocrine insufficiency resulting from congenital pancreatic agenesis. Am J Dis Child 147(6):607-609. https://doi.org/10.1001/archpedi.1993. 02160300013005

33. Tjora E, Wathle G, Erchinger F et al (2013) Exocrine pancreatic function in hepatocyte nuclear factor $1 \beta$-maturity-onset diabetes of the young (HNF1B-MODY) is only moderately reduced: compensatory hypersecretion from a hypoplastic pancreas. Diabet Med 30(8):946-955. https://doi.org/10.1111/dme.12190

34. Andersen DK, Korc M, Petersen GM et al (2017) Diabetes, pancreatogenic diabetes, and pancreatic cancer. Diabetes 66(5): 1103-1110. https://doi.org/10.2337/db16-1477

35. Dybala MP, Kuznetsov A, Motobu M et al (2020) Integrated pancreatic blood flow: bi-directional microcirculation between 
endocrine and exocrine pancreas. Diabetes 69(7):1439-1450. https://doi.org/10.2337/db19-1034

36. Chung KM, Singh J, Lawres L et al (2020) Endocrine-exocrine signaling drives obesity-associated pancreatic ductal adenocarcinoma. Cell 181(4):832-847.e18. https://doi.org/10.1016/j.cell.2020. 03.062

37. Aggarwal G, Kamada P, Chari ST (2013) Prevalence of diabetes mellitus in pancreatic cancer compared to common cancers. Pancreas 42(2):198-201. https://doi.org/10.1097/MPA. 0b013e3182592c96

38. Nyboe Andersen B, Krarup T, Thorsgaard Pedersen NT, Faber OK, Hagen C, Worning H (1982) B cell function in patients with chronic pancreatitis and its relation to exocrine pancreatic function. Diabetologia 23(2):86-89

39. Domschke S, Stock KP, Pichl J, Schneider MU, Domschke W (1985) Beta-cell reserve capacity in chronic pancreatitis. Hepatogastroenterology 32(1):27-30

40. Sheikh S, Gudipaty L, De Leon DD et al (2017) Reduced beta-cell secretory capacity in pancreatic-insufficient, but not pancreaticsufficient, cystic fibrosis despite normal glucose tolerance. Diabetes 66(1):134-144. https://doi.org/10.2337/db16-0394

41. Lundberg R, Beilman GJ, Dunn TB et al (2016) Early alterations in glycemic control and pancreatic endocrine function in nondiabetic patients with chronic pancreatitis. Pancreas 45(4):565-571. https:// doi.org/10.1097/MPA.0000000000000491

42. Moran A, Diem P, Klein DJ, Levitt MD, Robertson RP (1991) Pancreatic endocrine function in cystic fibrosis. J Pediatr 118(5): 715-723. https://doi.org/10.1016/S0022-3476(05)80032-0

43. Yi Y, Norris AW, Wang K et al (2016) Abnormal glucose tolerance in infants and young children with cystic fibrosis. Am J Respir Crit Care Med 194(8):974-980. https://doi.org/10.1164/rccm.20151225180C

44. Nyirjesy SC, Sheikh S, Hadjiliadis D et al (2018) Beta-cell secretory defects are present in pancreatic insufficient cystic fibrosis with 1-hour oral glucose tolerance test glucose $\geq 155 \mathrm{mg} / \mathrm{dL}$. Pediatr Diabetes 19(7):1173-1182. https://doi.org/10.1111/pedi.12700

45. Meier JJ, Giese A (2015) Diabetes associated with pancreatic diseases. Curr Opin Gastroenterol 31(5):400-406. https://doi.org/ 10.1097/MOG.0000000000000199

46. Norris AW, Ode KL, Merjaneh L et al (2019) Survival in a bad neighborhood: pancreatic islets in cystic fibrosis. J Endocrinol 241(1):R35-R50. https://doi.org/10.1530/JOE-18-0468

47. Iannucci A, Mukai K, Johnson D, Burke B (1984) Endocrine pancreas in cystic fibrosis: an immunohistochemical study. Hum Pathol 15(3):278-284. https://doi.org/10.1016/S0046-8177(84) 80191-4

48. Yi Y, Sun X, Gibson-Corley K et al (2016) A transient metabolic recovery from early life glucose intolerance in cystic fibrosis ferrets occurs during pancreatic remodeling. Endocrinology 157(5):18521865. https://doi.org/10.1210/en.2015-1935

49. Edlund A, Esguerra JL, Wendt A, Flodstrom-Tullberg M, Eliasson L (2014) CFTR and Anoctamin 1 (ANO1) contribute to cAMP amplified exocytosis and insulin secretion in human and murine pancreatic beta-cells. BMC Med 12(1):87. https://doi.org/10.1186/ 1741-7015-12-87

50. Guo JH, Chen H, Ruan YC et al (2014) Glucose-induced electrical activities and insulin secretion in pancreatic islet beta-cells are modulated by CFTR. Nat Commun 5(1):4420. https://doi.org/10. $1038 /$ ncomms 5420

51. Ntimbane T, Mailhot G, Spahis S et al (2016) CFTR silencing in pancreatic beta-cells reveals a functional impact on glucosestimulated insulin secretion and oxidative stress response. Am J Physiol Endocrinol Metab 310(3):E200-E212. https://doi.org/10. 1152/ajpendo.00333.2015
52. Hart NJ, Aramandla R, Poffenberger G et al (2018) Cystic fibrosisrelated diabetes is caused by islet loss and inflammation. JCI Insight 3(8):e98240. https://doi.org/10.1172/jci.insight.98240

53. Sun X, Yi Y, Xie W et al (2017) CFTR influences beta cell function and insulin secretion through non-cell autonomous exocrinederived factors. Endocrinology 158(10):3325-3338. https://doi. org/10.1210/en.2017-00187

54. White MG, Maheshwari RR, Anderson SJ et al (2019) In situ analysis reveals that CFTR is expressed in only a small minority of betacells in normal adult human pancreas. J Clin Endocrinol Metab 105(5):dgz209-dg1374. https://doi.org/10.1210/clinem/dgz209

55. Shik Mun K, Arora K, Huang Y et al (2019) Patient-derived pancreas-on-a-chip to model cystic fibrosis-related disorders. Nat Commun 10(1):3124. https://doi.org/10.1038/s41467-019-11178-w

56. Rafaeloff R, Pittenger GL, Barlow SW et al (1997) Cloning and sequencing of the pancreatic islet neogenesis associated protein (INGAP) gene and its expression in islet neogenesis in hamsters. J Clin Invest 99(9):2100-2109. https://doi.org/10.1172/JCI1 19383

57. Donowitz M, Hendler R, Spiro HM, Binder HJ, Felig P (1975) Glucagon secretion in acute and chronic pancreatitis. Ann Intern Med 83(6):778-781. https://doi.org/10.7326/0003-4819-83-6-778

58. Larsen S, Hilsted J, Tronier B, Worning H (1988) Pancreatic hormone secretion in chronic pancreatitis without residual betacell function. Acta Endocrinol 118(3):357-364. https://doi.org/10. 1530/acta.0.1180357

59. Aitken ML, Szkudlinska MA, Boyko EJ, Ng D, Utzschneider KM, Kahn SE (2020) Impaired counterregulatory responses to hypoglycaemia following oral glucose in adults with cystic fibrosis. Diabetologia 63(5):1055-1065. https://doi.org/10.1007/s00125020-05096-6

60. Klöppel G, Bommer G, Commandeur G, Heitz P (1978) The endocrine pancreas in chronic-pancreatitis. Immunocytochemical and ultrastructural studies. Virchows Arch A Pathol Anat Histol 377(2):157-174. https://doi.org/10.1007/BF00427003

61. Knop FK, Vilsboll T, Larsen S, Madsbad S, Holst JJ, Krarup T (2010) Glucagon suppression during OGTT worsens while suppression during IVGTT sustains alongside development of glucose intolerance in patients with chronic pancreatitis. Regul Pept 164(2-3): 144-150. https://doi.org/10.1016/j.regpep.2010.05.011

62. Lanng S, Thorsteinsson B, Roder ME et al (1993) Pancreas and gut hormone responses to oral glucose and intravenous glucagon in cystic fibrosis patients with normal, impaired, and diabetic glucose tolerance. Acta Endocrinol 128(3):207-214. https://doi.org/10. 1530/acta.0.1280207

63. Kelly A, De Leon DD, Sheikh S et al (2019) Islet hormone and incretin secretion in cystic fibrosis after four months of ivacaftor therapy. Am J Respir Crit Care Med 199(3):342-351. https://doi. org/10.1164/rccm.201806-1018OC

64. Norris AW (2019) Is cystic fibrosis-related diabetes reversible? New data on CFTR potentiation and insulin secretion. Am J Respir Crit Care Med 199(3):261-263. https://doi.org/10.1164/ rccm.201808-1501ED

65. Sive A, Vinik AI, Van Tonder S, Lund A (1978) Impaired pancreatic polypeptide secretion in chronicpancreatitis. J Clin Endocrinol Metab 47(3):556-559. https://doi.org/10.1210/jcem-47-3-556

66. Valenzuela JE, Taylor IL, Walsh JH (1979) Pancreatic polypeptide response in patients with chronic pancreatitis. Dig Dis Sci 24(11): 862-864. https://doi.org/10.1007/BF01324903

67. Nousia-Arvanitakis S, Tomita T, Desai N, Kimmel JR (1985) Pancreatic polypeptide in cystic fibrosis. Arch Pathol Lab Med 109(8):722-726

68. Uc A, Olivier AK, Griffin MA et al (2015) Glycaemic regulation and insulin secretion are abnormal in cystic fibrosis pigs despite sparing of islet cell mass. Clin Sci (Lond) 128(2):131-142. https://doi.org/10.1042/CS20140059 
69. Sun J, Ni Q, Xie J et al (2019) Beta-cell dedifferentiation in patients with T2D with adequate glucose control and nondiabetic chronic pancreatitis. J Clin Endocrinol Metab 104(1):83-94. https://doi.org/ 10.1210/jc.2018-00968

70. Hull RL, Gibson RL, McNamara $S$ et al (2018) Islet interleukin-1 $\beta$ immunoreactivity is an early feature of cystic fibrosis that may contribute to $\beta$-cell failure. Diabetes Care 41(4):823-830. https:// doi.org/10.2337/dc17-1387

71. Bogdani M, Blackman SM, Ridaura C, Bellocq JP, Powers AC, Aguilar-Bryan L (2017) Structural abnormalities in islets from very young children with cystic fibrosis may contribute to cystic fibrosisrelated diabetes. Sci Rep 7(1):17231. https://doi.org/10.1038/ s41598-017-17404-z

72. Eguchi K, Nagai R (2017) Islet inflammation in type 2 diabetes and physiology. J Clin Invest 127(1):14-23. https://doi.org/10.1172/ JCI88877

73. Xiao X, Gaffar I, Guo P et al (2014) M2 macrophages promote beta-cell proliferation by up-regulation of SMAD7. Proc Natl Acad Sci U S A 111(13):E1211-E1220. https://doi.org/10.1073/ pnas. 1321347111

74. Brissova M, Aamodt K, Brahmachary P et al (2014) Islet microenvironment, modulated by vascular endothelial growth factor-a signaling, promotes beta cell regeneration. Cell Metab 19(3):498511. https://doi.org/10.1016/j.cmet.2014.02.001

75. Tessem JS, Jensen JN, Pelli H et al (2008) Critical roles for macrophages in islet angiogenesis and maintenance during pancreatic degeneration. Diabetes 57(6):1605-1617. https://doi.org/10.2337/ $\mathrm{db} 07-1577$

76. Laferrere B, Pattou F (2018) Weight-independent mechanisms of glucose control after roux-en-Y gastric bypass. Front Endocrinol (Lausanne) 9:530. https://doi.org/10.3389/fendo.2018.00530

77. Javeed N, Sagar G, Dutta SK et al (2015) Pancreatic cancer-derived exosomes cause paraneoplastic beta-cell dysfunction. Clin Cancer Res 21(7):1722-1733. https://doi.org/10.1158/1078-0432.CCR14-2022

78. Wang Y, Ni Q, Sun J et al (2019) Paraneoplastic $\beta$ cell dedifferentiation in nondiabetic patients with pancreatic cancer. J Clin Endocrinol Metab 105(4):e1489-e1503. https://doi.org/10.1210/ clinem/dgz224

79. Sharma A, Smyrk TC, Levy MJ, Topazian MA, Chari ST (2018) Fasting blood glucose levels provide estimate of duration and progression of pancreatic cancer before diagnosis. Gastroenterology 155(2):490-500 e492. https://doi.org/10.1053/j. gastro.2018.04.025

80. Maitra A, Sharma A, Brand RE et al (2018) A prospective study to establish a new-onset diabetes cohort: from the consortium for the study of chronic pancreatitis, diabetes, and pancreatic cancer. Pancreas 47(10):1244-1248. https://doi.org/10.1097/MPA. 0000000000001169

Publisher's note Springer Nature remains neutral with regard to jurisdictional claims in published maps and institutional affiliations. 